\title{
The Call for Increased Surveillance and Public Health Measures to Monitor, Prevent, and Control Mosquito-Borne Disease Outbreaks in the Southern United States \\ Jimmy T Efird*
}

Department of Public Health and Center for Health Disparities, Body School of Medicine, East Carolina University, Greenville, NC, USA

Human infection with mosquito-borne diseases typically are caused by viruses belonging to the Togaviridae, Flaviviridae, and Bunyaviridae families [1]. Various forms of encephalitis (e.g., Eastern Equine, Western Equine, Venezuelan Equine, La Crosse, St. Louis, Powassan, Japanese, West Nile), Dengue Fever, and Chikungunyaare attributable to mosquito transmission. Their presence is amplified in the setting of vertebrate hosts such as wild birds and land animals (e.g., horses, chipmunks, tree squirrels), and less frequently humans and domestic animals (the latter lacking sufficient virema). However, humans are the primary host for dengue fever virus.

While mosquito-borne diseases have a global distribution, their frequency is greatest in tropical climates. However, mosquitos capable of transmitting viral disease are commonly found throughout the southern United States and disease outbreaks have occurred as far north as Philadelphia (1789 dengue fever), Chicago (1975 St. Louis encephalitis), and rural Wisconsin (1963La Crosse encephalitis) [24]. Disease emergence largely remains unpredictable. For example, following an island-wide epidemic of dengue fever in Taiwan in 1942, the disease was relatively contained until the fatal 1988 outbreak (10,000 reported cases) [5]. In the United Stately, a similar waxing and waning behavior has been observed for St. Louis encephalitis with recorded outbreaks in the state of Florida occurring in 1959, 1961, 1962, 1977, and 1990 [6]. Habitat encroachment, globalization, climate change, and defunding of mosquito abatement programs are some of the factors contributing to the incidence and re-emergence of mosquito-borne diseases. Substandard housing, crowding, poor water, sewer, and waste management systems also play an important role in disease transmission, especially in low-income regions [7]. The priority level afforded to mosquito-borne diseases parallels the sporadic nature of the outbreaks and competing governmental resources.

Neither currently available antiviral drugs nor antibiotics provide effective treatment for viral mosquito-borne diseases. Public health measures remain the best means for combating this problem. Efforts focused at the individual level include avoiding the outdoors in early evening hours, wearing appropriate barrier clothing to protect skin, and liberally applying mosquito repellent to exposed body parts [1]. Mosquitos rarely fly beyond 100 meters of their origin, thus facilitating targeted community-based mosquito control. The education of health authorities, medical providers and community leaders, active realtime surveillance (e.g., well-equipped public health laboratories, sentinel clinics, physician network, and fever alert system), systematic approaches to larval source reduction (e.g., eliminating water-holding containers such as old automobile tires, buckets, flower vases, and tin cans), and coordinated emergency response teams also represent effective public health efforts to monitor, prevent, and control future outbreaks [7]. Finally, the on-going monitoring of host animals and mosquito for virus activity is a critical component of a broad-based public health program [1].

\section{References}

1. Centers for Disease Control and Prevention (2005) Information on Arboviral Encephalitides.

2. Carey DE (1971) Chikungunya and dengue: a case of mistaken identity? J Hist Med Allied Sci 26: 243-262.

3. Zweighaft RM, Rasmussen C, Brolnitsky O, Lashof JC (1979) St. Louis encephalitis: the Chicago experience. Am J Trop Med Hyg 28: 114-118.

4. Thompson WH, Kalfayan B, Anslow RO (1965) Isolation of California encephalitis group virus from a fatal human illness. Am J Epidemiol 81: 245253.

5. Ko YC (1989) [Epidemiology of dengue fever in Taiwan]. Gaoxiong Yi Xue Ke Xue Za Zhi 5: 1-11.

6. Shroyer D, Rey J (2004) Saint Louis Encephalites: A Florida Problem Entomology and Nematology Department, Florida Cooperative Extension Service, Institute of Food and Agricultural Sciences, University of Florida. Document No. FMELMG227, October 2004.

7. Gubler DJ (1998) Dengue and dengue hemorrhagic fever. Clin Microbiol Rev 11: $480-496$.
*Corresponding author: Jimmy T Efird, Department of Public Health and Center for Health Disparities, Body School of Medicine, East Carolina University, Greenville, NC, USA, E-mail: EFIRDJ@ECU.EDU

Received September 21, 2013; Accepted September 24, 2013; Published September 27, 2013

Citation: Efird JT (2013) The Call for Increased Surveillance and Public Health Measures to Monitor, Prevent, and Control Mosquito-Borne Disease Outbreaks in the Southern United States. Trop Med Surg 1: e106. doi:10.4172/23299088.1000e106

Copyright: (c) 2013 Efird JT. This is an open-access article distributed under the terms of the Creative Commons Attribution License, which permits unrestricted use, distribution, and reproduction in any medium, provided the original author and source are credited. 